\title{
An analysis of correspondence of a training of specialists in a sphere of standardization and certification to the requirements of RF regions
}

\author{
Dmitriy Vasilega*, and Alena Zyryanova \\ Tyumen Industrial University, Volodarskogo Str., 38, 625000 Tyumen, Russia
}

\begin{abstract}
Nowadays standardization has a meaningful role for the modern society. But as all existing spheres, the standardization has a scope of problems. The most significant and important problem is a problem of the training of specialists in a sphere of standardization and metrology. This problem is expressed in discrepancy of quality and quantity of labor force to demands of the job market, consequently both population of a region and the state in general have great losses. We conducted a correlative analysis of a bonding force between a gross regional product of federal districts of RF and quantity of universities which train specialists in the field of study of 27.03.01 "Standardization and metrology" and also centres of standardization, metrology and tests (CSMT) and private test laboratories.
\end{abstract}

\section{Introduction}

With the purpose of refinement of the training of specialist in "Standardization and metrology" the work in introduction of Problem-based learning (PBL). Nowadays there a lot of papers which describe these particularities (De Graaff and Kolmos 2003; Beagon and et al 2019; Perez-Mejia 2019; Mesquita and et al 2020; Peyret and et al 2020; Busk Kofoed and et al 2020) и проблемы PBL (Reyes-Viviescas and et al 2020; García-Merino and et al 2020; Noordegraaf-Eelens and et al 2020; Stentoft 2019; Cargnin-Stieler 2019). The possibility of upgrading the Inverted Learning Model (FLM) is also being considered. A detailed description of research in this area is considered in the scientific results of scientists of the St. Petersburg Mining University (Marianna V. Voronina and et al 2017). Close attention should be paid to a professional orientation (Klochkov and et al 2017). But during basic public funding of training in "Standardization and metrology" as a basic direction for provision of unity of measurements there appeared a significant problem of interconnection between quantity and quality of specialists of this sphere which are required by economics and quantity and quality of graduates of this faculty, especially from the point of view of regions of RF. And if most part of problems with quality of the specialists training during the introduction of PBL can be resolved, especially in case of actualization of PBL together with the basic organizations (Andersen, Brunoe, Nielsen

\footnotetext{
*Corresponding author: d_vasilega@mail.ru
} 
2019), then the problem of identification of correspondence of quantity of specialist under training to the requirements of economy is particularly acute. State regional centers of standardization, metrology and tests (CSMT) can be used as these basic organizations. This paper is devoted to this problem solution.

The basic part.

Nowadays there 90 universities of different levels in Russian Federation which train specialists in the field of study of 27.03.01 "Standardization and metrology". 79 state regional centers of standardization, metrology and tests (CSMT) are registered in RF besides the abovementioned higher institutions.

Also, we took into consideration a ratio of a level of the gross regional product (GRP) of each region in Russia. Leading federal districts according to the ratio in total of GRP in 2018 are Central, Volga and Ural (34,8\%, 15,5\%, $13 \%$ correspondently), according to the ratio in total of investment in equity in 2018 - also Central, Volga and Ural $(25 \%, 18,1 \%$, $15,6 \%$ correspondently).

An amount of the organizations (HU, CSMT) of federal districts of Russian Federation and the ratio of the gross regional project are presented on Fig. 1.

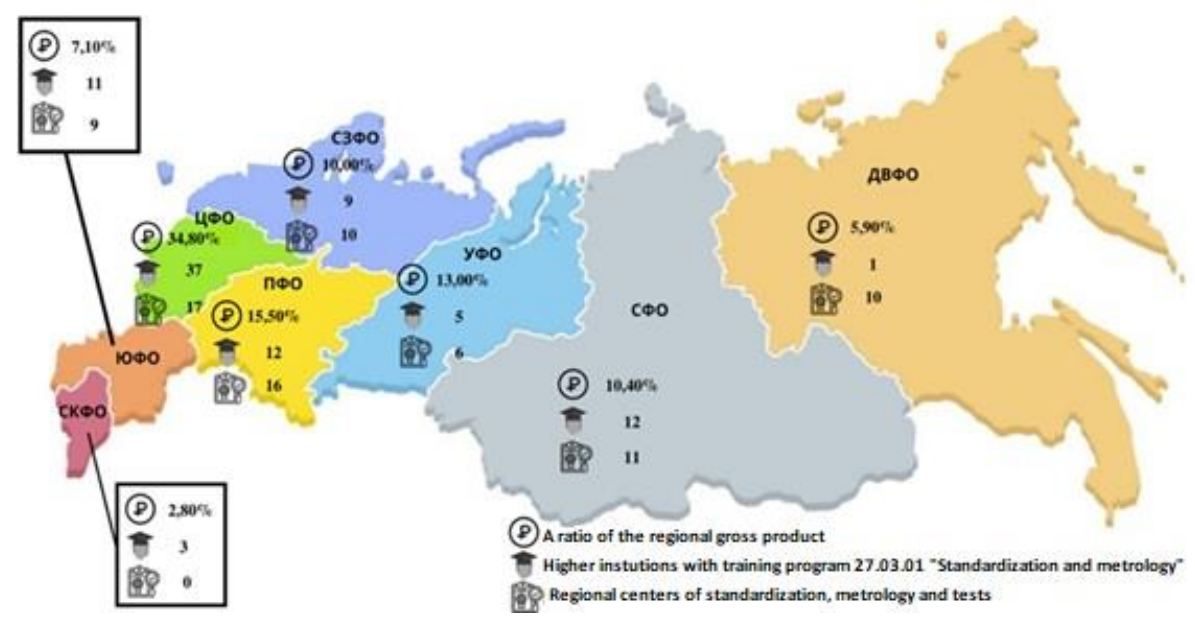

Fig. 1. Quantity of organizations (Higher institutions, CSMT) of federal districts of Russian Federation and the ratio of the regional gross product

Where: СЗФО - North-Western Federal District (NWFD); ЦФО - Central Federal District (CFD); ЮФО - Southern Federal District (SFD); СКФО - North-Caucasian Federal District (NCFD); ПФО - Volga Federal District (VFD); УФО - Ural Federal District (UFD); СФО - Siberian Federal District (SFD); ДВФО - Far Eastern Federal District (FEFD).

We conducted the correlative analysis in order to estimate the bonding force of the regional gross product and higher institutions which train specialist in the field of study of 27.03.01 "Standardization and metrology" and the centers of standardization, metrology and test which provide both work places for specialist of this level of education and services in the sphere of standardization and metrology in a real sector of economy of the country.

Let us compute coefficients of correlation $\mathrm{r}$ according to formula:

$$
r=\frac{N \sum X Y-\left(\sum X\right) *\left(\sum Y\right)}{\sqrt{\left(\left[N \sum X^{2}-\left(\sum X\right)^{2}\right] *\left[N \sum Y^{2}-\left(\sum Y^{2}\right]\right)\right.}}
$$

where $\mathrm{N}-$ is a quantity of rates or elements; 
$\mathrm{X}$ - is a quantity of higher institutions, which train specialist in the field of study of 27.03.01 "Standardization and metrology"/a quantity of the state regional centers of standardization, metrology and tests;

$\mathrm{Y}$ - ratio of total of the gross product of the federal districts, \%.

Criteria of the bonding force are estimated according to Cheddok scale:

$0,1<\mathrm{r}<0,3$ - weak connection (very weak correlation);

$0,3<\mathrm{r}<0,5-$ temperate connection (weak correlation);

$0,5<\mathrm{r}<0,7-$ significant connection (medium correlation);

$0,7<\mathrm{r}<0,9$ - high connection (high correlation);

$0,9<\mathrm{r}<1-$ very high connection (very high correlation).

In case when $r=0$, both variables are deemed to be linearly independent form each other.

Using formula (1), let us find the correlation coefficient value in dependence Higher Institution - GRP:

$\mathrm{r}=0,9363775898072896$

The value of the correlation coefficient in dependence CSMT - GRP:

$\mathrm{r}=0,7282166658307767$

The value of the correlation coefficient in dependence CSMT - Higher institution:

$\mathrm{r}=0,6934459180720107$

According to the received date we can make a conclusion that:

- the bonding force between the quantity of higher institutions which train specialist in the field of study 27.03.01 "Standardization and metrology" and the volume of the regional gross product is at very high level $(0,9363775898072896)$;

- the bonding force between the quantity of the regional centers of standardization, metrology and test and the volume of the regional gross product is at very high level $(0,7282166658307767)$;

- the bonding force between the quantity of higher institutions which train specialist on the field of study of 27.03.01 "Standardization and metrology" and the quantity of the regional centers of standardization, metrology and tests is at very high level $(0,6934459180720107)$.

For clarity of conduction of the correlation analysis we constructed a graph of the dependence of the quantity of the organizations (Higher institutions, CSMT) among the federal districts of Russian Federation and the ratio of the regional gross product. The graph is presented on Fig. 2.

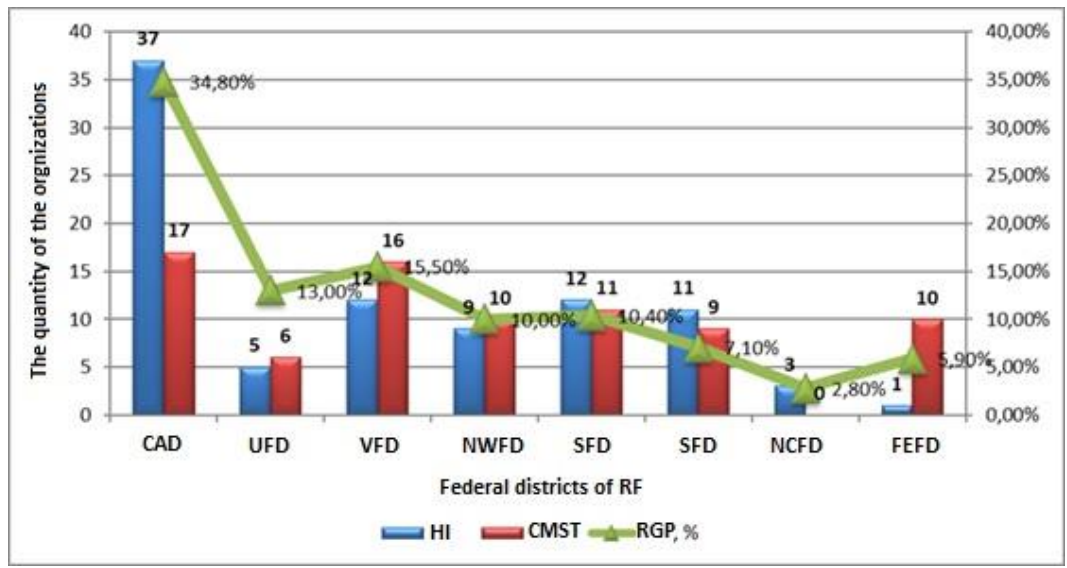

Fig. 2. The dependence of the quantity of the organization (HI, CSMT) among the federal districts of Russian Federation and the ratio of the regional gross product 
Low-level values of the correlation in last two cases are obviously caused by presence of test laboratories besides state CSMT.

According to the unified register of the test laboratories there are about 1605 working private test laboratories in Russia.

As a result of the analysis of the dependencies of the organizations (HI, CMST) among federal districts of Russian Federation and the ratio of the regional gross product we found out the following:

- in the central administrative district, the quantity of academic institutions with training program of specialists 27.03.01 "Standardization and metrology" is significantly different from the quantity of the regional centers of standardization and metrology, but however, this level of the regional gross product is rather high and is $34,8 \%$. That is the highest rate on the territory of Russian Federation. Such high values of RGP suppose a big volume of works in a sphere of metrology and standardization and we can assume that the private test laboratories undertake deficient volumes of work in this sphere.

- in Ural federal district we can see a balance between the quantity of the regional centers of standardization and metrology and the quantity of higher institutions which train specialist in the field of study of 27.03.01 "Standardization and metrology", but the lowlevel correlation dependence between these two regional centers of standardization and metrology an RGP value show a lack of specialists in this sphere;

- in Volga, north-western, southern federal districts we can see a balance between the quantity of educational organizations and the quantity of the regional centers of standardization and metrology, moreover they all have a tight correlation connection with the level of the regional gross product;

- there are no centers of standardization, metrology and tests in north-Caucasian federal district, but there 3 universities with training program 27.03.01 "Standardization and metrology" and we can suppose that the required volume of works of standardization and metrology is conducted by the private test laboratories. But doubts occur as to necessity of the training if the specialists in implemented quantity. Also, from the picture we can see that the level of the regional gross product is $2,8 \%$, that is the lowest value among RGPs of all federal districts;

- far eastern federal district has 10 regional centers of standardization, metrology and tests and only 1 university with graduates of 27.03.01 "Standardization and metrology" training program. Taking into account temps of the region development we can forecast a lack of specialists in sphere of metrology and standardization anytime soon. The ratio of the regional gross product in this region is 5,9\%, that is the lowest value on the territory of Russia. The key economics sector of far eastern federal district are - natural resources, transport and communictions, but nevertheless, problems of the logistics systems are a constraining factor for a growth of GRP ratio.

With the purpose of getting of nuanced picture about matter of practicability of the training of specialists of 27.03.01 "Standardization and metrology" training program in each district we analyzed the information about quantity of the private test laboratories. It is presented on Fig. 3.

Taking into consideration the new information we can make the following conclusions:

- an assumption that these are the test laboratories that undertake deficient volumes of work in the sphere of standardization and metrology in central administrative district was confirmed. Moreover, the private test laboratories do not only create work place for specialists of a necessary level but also provide the regional economics with the necessary set of services in the region under study;

- in Ural federal district we can suppose a lack of specialists in the sphere of standardization and metrology corresponding to demands of the market. With such big quantity of the private test laboratories and state centers of standardization and metrology 
only five universities conduct the training of specialists of 27.03.01 "Standardization and metrology" training program;

- in Volga, north-western, Siberian, southern federal districts graduation of the specialists in the sphere of standardization and metrology correspond to the declared needs in the sphere of labor force training;

- in north-Caucasian federal district graduation of the specialists in the sphere of standardization and metrology overtops significantly the declared needs of the enterprises in the training of specialists, but herewith, maybe, there is a labor migration of these specialists in other regions of the country;

- in far eastern federal district we found out a lack of the specialists in the sphere of standardization and metrology and in connection with that we made a conclusion about necessity of increase of quantity of labor force under training in the field of study of 27.03.01 "Standardization and metrology".

In order to solve the problem of discrepancy of supply and demand on the job market we need to conduct a whole package of measures:

- it is required to study the market constantly concerning vacancies in the sphere of standardization and metrology;

- educational organizations should actively cooperate with employers of the region, organize practical-module education, graduates fairs;

- increase quality of the educational process, maintain educational and professional standards;

- create an informational portal with fresh information about necessary specialities in each of the regions.

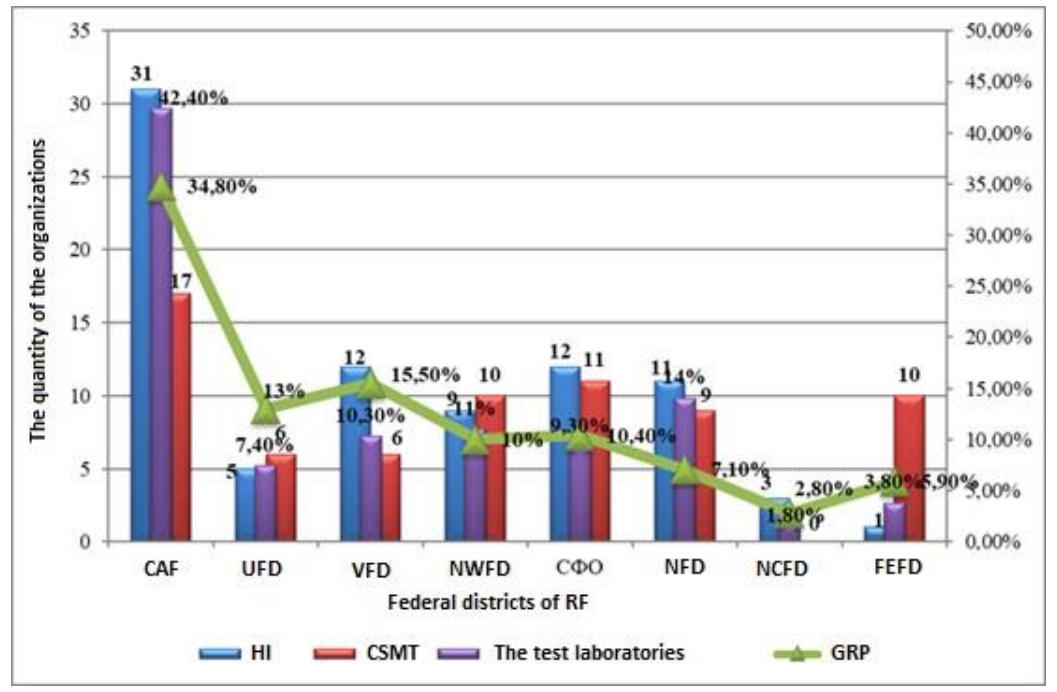

Fig. 3. The dependence of the quantity of the organization (HI, CSMT, the private test laboratories) among the federal districts of Russian Federation and the ratio of the regional gross product

The social labor sphere, sphere of the country economics undergoes constant changes, regions of RF differ significantly by resource provision, economical and financial values, industrialization process, industry, social infrastructure. It all must not be taken into consideration during an organization of cooperation between educational and industry bases. The training of the specialists in the sphere of standardization and metrology is required to keep a balance of supply and demand on the job and educational markets. And the conducted analysis gives an opportunity to study thoroughly and consequently resolve this problem for each region of Russia. The profile of the educational institutes should 
correspond to definite needs and goals of development both for each region of RF and for the whole country in general.

\section{Conclusions}

As a result of the analysis we found out the following:

In central administrative district we can see enough quantity of the specialists trained in the field of study 27.03.01 "Standardization and metrology", the required level of works in the sphere of standardization and metrology is conducted not only by the regional CSMT but also by the private test laboratories;

In Volga, north-western, Siberian, southern federal districts graduation of the specialist in the sphere of standardization and metrology corresponds to the declared needs in the labor force training;

In north-Caucasian federal district graduation of the specialists in the sphere of standardization and metrology overtops significantly the declared need of enterprises in the training of qualified specialists;

In Ural and far eastern federal districts we found out a lack of the specialists in the sphere of standardization and metrology and in connection with that, we made a conclusion about necessity of increase of quantity of the trained labor force in the field of study of 27.03.01 "Standardization and metrology".

It is necessary to understand what quantity of trained specialists in the sphere of standardization and metrology is required in order to keep the balance of supply and demand. And the conducted analysis gives an opportunity to study thoroughly and consequently resolve this problem for each region of Russia.

\section{References}

1. A.L. Andersen, T.D. Brunoe, K. Nielsen, Procedia CIRP, 81, 7 (2019)

2. U. Beagon, D. Niall, N. Fhloinn, Problem-based learning: student perceptions of its value in developing professional skills for engineering practice, 44(6), 850 (2019)

3. L. Busk Kofoed, J.R. Bruun-Pedersen, N. Svarre Kristensen, L.B. Andreasen, Integration of courses and projects - Disrupting a traditional PBL semester structure, 1469 (2020)

4. M. Cargnin-Stieler, M.T. Malheiro, A.C. Alves, R.M. Lima, M.C. Teixeira, Advances in Engineering Education, 7(3), 28 (2019)

5. E. De Graaff, A. Kolmos, International Journal of Engineering Education, 19(5), 657 (2003)

6. J.D. García-Merino, S. Urionabarrenetxea, A. Fernández-Sainz, Does PBL improve student performance in a multidimensional way? A proposal for a moderated mediation model (2020) https://www.scopus.com

7. Y.S. Klochkov, A.I. Lepehin, D.S. Vasilega, N.A. Vasilega, K.Z. Nonieva, S.E. Vasilyeva, professional orientation of students, 165 (2017)

8. D. Mesquita, T. Salimova, E. Soldatova, S. Atoev, R.M. Lima, What can be recommended to engineering teachers from the analysis of 16 European teaching and learning best practices, 770 (2020)

9. L. Noordegraaf-Eelens, J. Kloeg, G. Noordzij, Advances in Health Sciences Education, 24(5), 971 (2020) 
10. A.A. Perez-Mejia, Call it what you want: Blending project-based learning and the flipped class-room model in a Civil Engineering course (2019), https://www.scopus.com

11. N. Peyret, S. Courtois, G. Chevallier, Combined project-based learning and teacherpractical demonstrations to help acquire global engineering skills, 871 (2020)

12. D. Reyes-Viviescas, E. Ventura-Medina, T. Anderson, C. Mio, Development of learner autonomy in student-centred learning environments in engineering, 899 (2020)

13. D. Stentoft, Problem-based projects in medical education: extending PBL practices and broadening learning perspectives, 24(5), 959 (2020)

14. M.V. Voronina, et al., Eurasia Journal of Mathematics, Science and Technology Education, 8, 4831 (2017) 